\title{
Research and Application of the Combination of Online and Offline Teaching Mode in Organic Chemistry
}

\author{
Hongjie Qu*, Yafei Wang, Taifan Sun, Jinyan Zhang, Jinling Gao, Hongmei Bi, Fengying Xu
}

College of Science, Heilongjiang Bayi Agricultural University, Daqing, 163319, Heilongjiang Province, P. R. China

DOI: $10.36347 /$ sjavs.2021.v08i01.001

| Received: 19.12.2020 | Accepted: 05.01.2021 | Published: 09.01.2021

*Corresponding author: Hongjie Qu

Abstract

Review Article

Facing the current situation of organic chemistry courses in colleges and universities, such as too much content, insufficient class hours, insufficient students' absorption and inadequate practice, this paper effectively introduces the combination of online and offline teaching mode in the teaching process of organic chemistry. This teaching mode is diversified and has strong advantages. It gives full play to the leading role of teachers in guiding, inspiring and supervising in the teaching process, stimulates students' interest in learning, promotes teachers' teaching reform ability, and achieves good teaching effect.

Keywords: Organic Chemistry; the combination of online and offline; teaching mode; research and application.

Copyright $\odot 2021$ The Author(s): This is an open-access article distributed under the terms of the Creative Commons Attribution 4.0 International License (CC BY-NC 4.0) which permits unrestricted use, distribution, and reproduction in any medium for non-commercial use provided the original author and source are credited.

\section{BACKGROUND}

Any reform of "teaching" and innovation of "learning" must start with the original intention of students' learning state and learning effect [1]. General Secretary Xi Jinping has pointed out that "Innovation is the productive force. Enterprises rely on it for strength and the country relies on it for prosperity". Therefore, college education and teaching should follow the trend of reform and development, seize the opportunity and realize the synergy of digitalization, networking and intelligentization. It is necessary to constantly explore new modes, new forms and new ways of teaching reform and development, so as to build the modern Silk Road which belongs to the mode of digitalization teaching in colleges and universities. Since 2016, the Ministry of Education has issued relevant policy documents [2,3] on guiding institutions of higher learning to formulate supporting policies and carry out inter-school course recognition and credit recognition, so as to encourage and support the construction and application of online open courses in institutions of higher learning. For example, Massive Open Online Courses (MOOC), Micro-lecture, Small Private Online Course (SPOC), Flipped Classroom and other emerging educational and teaching models are rapidly developed [4]. The combination of online and offline teaching reform has been constantly explored and practiced [5]. The teaching mode of "the combination of online and offline" is an open teaching mode integrating new network information technology with traditional teaching methods. It organically combines the advantages of online teaching and traditional offline teaching to form a new teaching mode that is more conducive to teachers' "teaching" and more suitable for students" "learning". This mode of teaching is flexible and the classroom is easy to be flipped, which can not only stimulate and improve students' autonomy in learning, but also give full play to teachers' enlightening and guiding role.

\section{Current situation and existing problems of organic chemistry course \\ Organic chemistry is an important public} compulsory course for the majors of biology, food and agriculture in our university. Organic chemistry is rich in content, theoretical and systematic. Simultaneously, it also involves a lot of three-dimensional, abstract and reaction mechanism of chemical problems. But at present the high quality teaching resource is short and the supply is insufficient, the teaching modernization degree is weak and so on [6], the traditional teaching method which mainly inculcates has some drawbacks.

Firstly, the teaching method is relatively unitary. The course content of organic chemistry is relatively difficult, with many knowledge points. It requires students to master solid basic knowledge and reaction rules, and be able to analyze and solve problems well. However, the traditional single teaching 
is dominated by teachers' "teaching", and students accept passively. Even if they often use questions or inspire teaching, students' initiative has not been significantly improved. The teaching model can no longer meet the needs of organic chemistry teaching.

Secondly, there are not enough teaching hours in the classroom. The teacher felt that he could not explain the important knowledge points thoroughly, nor could he do enough exercises in the limited time, nor could he do the teacher-student interaction fully. Most of the students also felt that they practiced in a hurry, which was not conducive to the cultivation of students' thinking and exploration ability. There is no time for students to infiltrate, no time for thinking and politics, or even to finish the course in a hurry. Due to the limitation of small class hours, the extent of questioning or enlightening teaching methods will be limited, and the teaching effect is not ideal.

Lastly, solid and abstract chemical problems are not intuitive. Organic chemistry involves a lot of solid and abstract chemical problems, but in the plane of the blackboard will be not intuitive, and difficult to understand. When we use multimedia to introduce animation or video, it will take up a lot of class time, which will directly lead to the teaching schedule of other contents.

Based on the current teaching situation of organic chemistry in colleges and universities, the best way is to change the existing teaching mode and carry out the research and application of online and offline teaching mode.

\section{Advantages of the combination of online and offline teaching mode of organic chemistry}

Relying on the wisdom Tree platform, the organic chemistry teaching team of our teaching department has completed the recording of the Organic Chemistry MOOC, with which the explanation of each chapter is very detailed and specific, and the prominent points and distinct difficulties. Teachers will be released in 3 days before the class next single classroom, including the teaching contents and learning to master the knowledge points, and some related problems and requirements, the students can "problem for the line, with knowledge", took the issue to study, study after they have been summarized this study targeted, targeted, but also cultivate the students' self-study ability and self-discipline, urge the students of class learning sharing curriculum section. The advantages of the combined online and offline teaching mode of organic chemistry over traditional teaching are as follows:

Firstly, students are free from time constraints and have more initiative in their study. Students should be free to watch organic chemistry MOOC courses within a limited time according to the requirements of teachers. Moreover, students can learn knowledge points that they lack or have not mastered accurately repeatedly, which is conducive to a profound understanding and mastery of knowledge. This way of learning alleviates the pressure in the class caused by the intense class hours.

Secondly, students practice more fully. Each video of the MOOC course is filled with bullet questions, which is a little practice after each knowledge point, so that students can get timely application. Moreover, the course system also includes test questions and question banks of each chapter, so that students can get more practice and practice. Because students have learned the contents of MOOC before class, they can have more practice time in class and practice the exercises related to key knowledge more deeply, which is conducive to students' application of knowledge.

Thirdly, stereo and abstract problems are more intuitive. When explaining Newman projection, optical rotation isomerism, orbital bonding and other chapters, teachers used ball-stick model or video animation, enabling students to master these abstract and difficult knowledge from an intuitive three-dimensional perspective.

Fourthly, in the offline teaching part, the interaction between teachers and students should be increased to flip the classroom. Many college teachers have vigorously carried out "flipped classroom" teaching under the combination of online and offline teaching mode, which has greatly improved students' learning autonomy and learning ability [7]. Students can fully participate in the summary of knowledge points and answer questions, which makes our classroom become a "teacher-guided, student-centered" class, and also makes our classroom completely flip up. Teachers supplement the key and difficult points, issue practice questions for students to answer, call the students to explain at random, and make supplement. In this way, students' mastery of this question can be understood, and student-centered teaching can be realized.

Fifthly, appropriate elements of ideological and political education should be added. The dynamic integration of basic teaching and ideological and political education enhances students' professional confidence, national pride and social responsibility. In the teaching design, the course ideological and political links can be timely added. The course ideological and political resources mining lies in "telling Chinese stories well" to students and cultivating students' patriotism. "Tell stories of good masters" to cultivate students' truth-seeking consciousness in scientific research; "Tell good stories around" to cultivate students' observant thinking of discovery; At the same time into the view of science and scientific methods, cultivate students' scientific cognitive spirit, improve the quality of student talent training. 
Lastly, The teacher's pre-class teaching design and teaching preparation are very important. In order to attract students' attention, make students' independent learning effective, so as to ensure the quality and quantity of teaching tasks, teachers must carefully perceive the students, lead the students, do the full design preparation before class. "Glimmer torch, trickling water into a river", whether teachers or students, the drop of sweat, together into an invisible force, we spread every sweat, are sending out a different taste. Teachers and students are in constant efforts and exploration, the university's teaching model will continue to mature and expand.

\section{Summary of Teaching Practice}

The emergence of the combination of the online and offline teaching mode is the inevitable trend of the development of higher education teaching in the age of digitization, information and network. Based on the characteristics of the teaching content, the combination of the online and offline teaching mode is more effective in the application of organic chemistry courses. Compared with single online live teaching or traditional offline classroom teaching, this combination of the online and offline teaching mode has unique advantages. The application of the online and offline teaching mode greatly improves the teaching effect of organic chemistry. The application results show that students' acceptance of the online and offline teaching mode is higher, which makes students' learning style, learning time and participation more flexible, and greatly improves students' autonomy and enthusiasm in learning. This model can not only give full play to the leading role of teachers in guiding, enlightening and supervising in the teaching process, but also ensure the subjectivity of students in the learning process, so as to achieve better teaching effect by truly transforming teachers' "teaching" as the center to students' "learning" as the center. At the same time, we also hope that the combination of online and offline teaching mode of organic chemistry can bring some help and reference to the teaching reform of other public courses.

\section{Fund Project}

1. Research and Practice on the Construction of "Golden Course" in Organic Chemistry based on the Combination of online and offline Teaching Mode by Heilongjiang Education Department in 2019 (Serial number: SJGY20190472).

2. Heilongjiang Bayi Agricultural University "Curriculum ideological and Political" teaching reform project, course name: Organic analysis.

\section{REFERENCES}

1. Fang L, Li-Ting W. New research methods of college students' learning states under background of big data. Heilongjiang Researches on Higher Education. 2019; (12):143-147.

2. Ministry of Education. Guidelines of the Ministry of Education on deepening educational and Teaching Reform in Universities affiliated to central Departments [A/OL]. (2016-06-13)[201901-07].

3. Ministry of Education. Opinions of the Ministry of Education on promoting credit Recognition and Transfer in Higher Education [A/OL]. (2016-0918)[2019-01-07].

4. Shu-Xia H, Zhi-Wei B, Jie W. Teaching practice of large-scale calculus class based on SPOC blended teaching mode. Higher Education of Sciences. 2019; 143(1):62-73.

5. Ying-Chun L, Qi W, Lin-Jun W. Exploration of online and offline teaching model on advanced physical chemistry. Higher Education of Sciences. 2019: 4(146):68-71.

6. Qing-Quan L, Jun L, Zhong-Mei S, Yan-Ling W. Exploration of teaching Reform in local Colleges and universities based on MOOC. Chinese University Science \& Technology. 2018; (3): 810.

7. Zhi-Guo G. "Micro-course" background: practice and exploration of offline, online and offline mixed teaching mode — taking Animal Welfare as an example. The wind of science and technology. 2020: 12:52-53.

8. Ying L, Jiao Y, A-juan Y. Exploration and construction of "Curriculum Ideology and Politics" and "Online + offline" practical teaching model. Education Teaching Forum. 2020; 12(50):59-60. 